\title{
1. Environmental dystopia versus sustainable development utopia: roles of businesses, consumers, institutions, and technologies
}

\section{Duane Windsor}

\section{INTRODUCTION}

This chapter contrasts an environmental dystopia scenario with a sustainable development utopia scenario. The dystopia is here labeled "1984" in order explicitly to evoke George Orwell's 1984 (1949) repressive totalitarian regimes - which might result from global environmental catastrophe. The original forecast for "1984" was, in effect, perpetual war among super-powers. H. G. Wells' vision of the future might be characterized as "anarchy" rather than structured perpetual war (Rothbard, 2013). The utopia is here labeled "Brave New World" in order to evoke Aldous Huxley's Brave New World (1932) satire of scientific and social progress. The dystopia is a "nightmare" and the utopia is a "dream" (Scott, 2017). Utopian thinking may even involve a "leap of faith" going well beyond a "dream" (Kingstone, 2017). The dystopian nightmare would be an environmental "waste land" (Podgajna, 2014).

The purpose of the contrast is to help sharpen understanding of two extreme alternatives for the future: either the world environment, whether slowly or more dramatically, begins to fail toward a global catastrophe tipping point; or the world environment, whether slowly or more dramatically, begins to improve away from such a global catastrophe tipping point (Morello, 2012; Russill, 2015).

Some scientific estimates concerning the achievement of the climate change goals of the 2015 Paris Agreement in force November 4, 2016 (UN Framework Convention on Climate Change, 2015) are quite pessimistic (Associated Press, 2016; Jones and Warner, 2016). This skepticism concerning governmental policy change outcomes presumably throws greater burden on businesses, consumers, non-governmental institutions, 
and technology solutions. Skepticism tends to tilt predictions toward the environmental dystopia scenario (Crowley, 2010). Technology solutions are uncertain - depending greatly on science, engineering, and entrepreneurship (Beder, 1994), in relation to speed of environmental and developmental deterioration toward tipping points.

Resolving the policy debate concerning carbon tax versus cap-andtrade may be considerably less important than picking at random and acting as soon as possible (Keohane and Wagner, 2015). China reportedly announced plans to introduce a cap-and-trade approach during 2017 (Osborne, 2017). A newly formed blue ribbon climate coalition, including prominent business executives and ex-USA government officials, supported a "The Conservative Case for Carbon Dividends" proposal to tax carbon emissions and return the resulting funds to USA taxpayers in the form of a dividend (Osborne, 2017). The proposed tax would be $\$ 40$ per ton, rising over time. There would also be a border tax on carbon produced by importers to deter free-riding, and adjustments to existing regulations. The estimated dividend could be $\$ 2,000$ per average four-person family (Osborne, 2017). One commentator expressed reservations about whether the proposal would become law under present circumstances (Taylor, 2017).

The least-developed knowledge concerns likely roles of businesses, consumers, and non-governmental social institutions. The problem is how to motivate more ethical and sustainable behaviors. The chapter will identify literature bearing on this problem. While B Corporation and social enterprise entrepreneurs may be motivated by sustainable development concerns, it is unreasonable - in the absence of governmental incentives, positive and negative - to expect profit-oriented corporations to solve climate change and other environmental tipping point problems (Oreskes and Schendler, 2015; Strine, 2012). New technologies would have to be highly profitable. Hence, there must be a change in the population of businesses and a change in governmental incentives for businesses. To what extent consumers will voluntarily bear increased public taxes and private taxes in order to address sustainability is not well understood notwithstanding an expanding literature (Black and Cherrier, 2010; Head et al., 2016). Institutional redesign for pro-sustainability outcomes is in an early stage of research (Bednar, 2016).

This introduction has explained the motivation for the chapter. The remainder of the chapter is organized as follows. The following section explains the definitions of, and differences between, scenarios and forecasts. This chapter does not forecast the future, although it suggests that present evidence seems pessimistic and "edgy" rather than optimistic concerning the future. The third section explicates the dystopian environmental 
catastrophe nightmare scenario. The fourth section explicates the utopian sustainable development scenario. The fifth section speculates about the possible configuration of a "2084" world; and discusses the possible roles of businesses, consumers, institutions, and technologies in shaping that "2084" configuration. The chapter concludes with a final section that summarizes key points and implications.

\section{SCENARIOS AND FORECASTS}

Figure 1.1 provides a simple depiction of the relationship between the optimistic "Brave New World" of sustainable development utopia and the pessimistic "1984" of environmental catastrophe dystopia. The horizontal axis of the depiction is the flow of time, from present (today) to future (tomorrow). Along the vertical axis, the positive outcome leads upward toward sustainable development; the negative outcome leads downward toward environmental catastrophe. Upward is toward "Brave New World" - where we all want to go; downward is toward "1984" which we all want to avoid. We do not know if there are upper and lower limits for sustainable development and environmental catastrophe; and thus such limits are not indicated in the Figure 1.1 depiction.

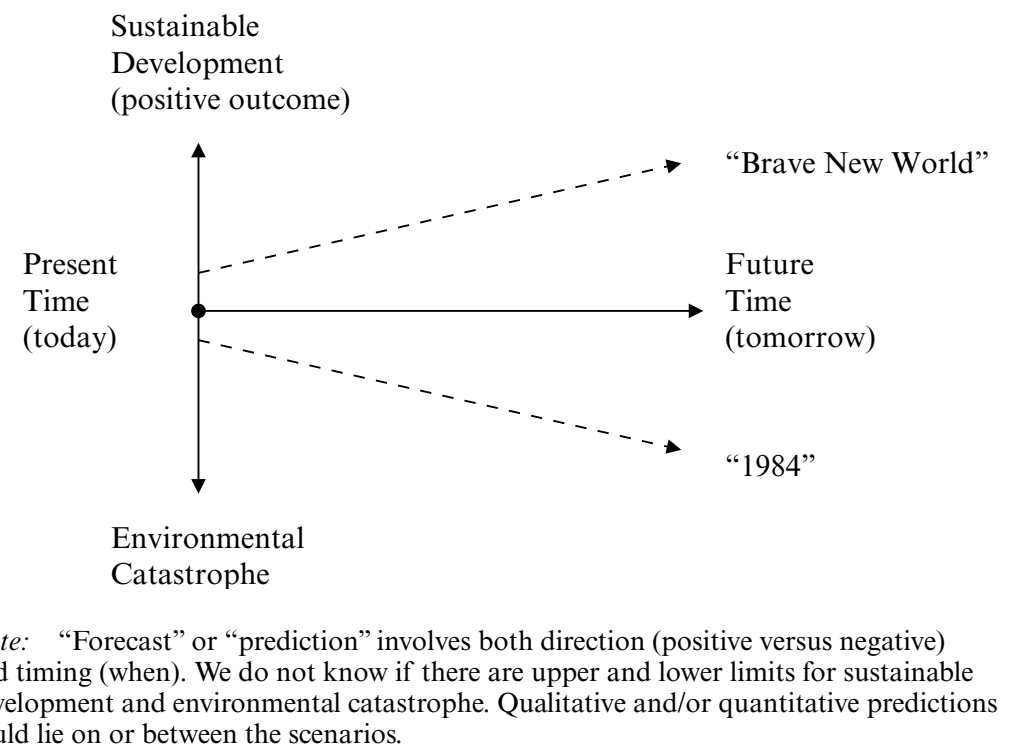

Figure 1.1 Two contrasting scenarios for tomorrow's global environment 
Figure 1.1 does not include or suggest a specific forecast or prediction. Scenario contrasting is not a forecast or prediction as such; rather it is an exploration of effectively opposed possible outcomes. The empirical path forward in time may be one of the two contrasting scenarios, or some outcome lying between the two extreme scenarios. A possibility might be cycling, over time, upward toward better sustainable development and downward toward worsening environmental catastrophe. This possibility might come with an early tipping point or a late tipping point toward environmental catastrophe, or with a set of technological miracles that move away from environmental catastrophe. Qualitative or quantitative predictions could lie on or between the two broad scenarios (see Booth et al., 2016). A qualitative scenario or prediction is a narrative. A quantitative scenario is typically in the form of a model such as underlies the findings reported by Jones and Warner (2016).

Narratives about the global environmental situation tend to emphasize that a catastrophe is inevitable unless there is immediate action (the forecast is that " 1984 " is coming fast) or that climate change is being hyped (the forecast is that a "Brave New World" due to technology miracles and sustainable development is coming instead of "1984"). Scenario contrasting is also not a foundation for specific recommendations, which are bundled with the forecasts. However, given uncertainty about the future, a strategic posture arguably might be to prepare for the worst while continuing to hope for the best.

The scenario contrast approach draws on the long traditions of "utopia" and "dystopia" fiction (literature and film). The utopia tradition arguably begins with Sir Thomas More's Utopia (1516). The dystopia tradition arguably begins with $\mathrm{H}$. G. Wells' bleak science fiction works challenging scientific progress and similar literature, utopian and dystopian, from the late nineteenth century (Claeys, 2010; Kingstone, 2017). ${ }^{1}$

A standard dictionary definition of a utopia emphasizes three attributes: (1) the utopia is imaginary and remote in time and distance; (2) the utopia is a "no" place of ideal (or near-ideal) perfection; and (3) the utopia is thus presently an impractical scheme for future improvement (https://www. merriam-webster.com/dictionary/utopia). Sir Thomas More invented the term for his book Utopia (1516), from Greek words for "no" and "place" (https://www.merriam-webster.com/dictionary/utopia). A standard dictionary definition of a dystopia, or anti-utopia, is an equally imaginary "no" place in which conditions are the opposite of utopia as paradise (https:// www.merriam-webster.com/dictionary/dystopia). An environmental dystopia is the polar-opposite of a sustainable development utopia. ${ }^{2}$

A standard dictionary definition of a scenario is a narrative description - typically in synopsis form - of a possible sequence of imagined events 
(https://www.merriam-webster.com/dictionary/scenario). A scenario can be qualitative or quantitative in comment. The qualitative approach is used in this chapter, while quantitative information is restricted to forecasts or predictions.

The literature emphasizes that environmental scenarios (see Börjeson et al., 2006; O’Neill et al., 2008) are essential to addressing environmental problems effectively through collaborative action (Wilkinson and Eidinow, 2008). These narratives should desirably be scientific and compelling in order to inform climate change conversation (Segal, 2017). Otherwise, the conversation becomes dominated by non-scientific approaches such as self-interest in place of public interest (see Sinclair and Diduck (2017) on public participation aimed at identifying the public interest).

Wilkinson and Eidinow identify three types of environmental scenarios: problem-focused, actor-centric, and RIMA (for "reflexive interventionist or multi-agent based"). The authors identify the initial two scenarios from existing approaches and propose RIMA as a third approach that combines epistemologies from the other two scenarios to provide a better bridge between longer-term thinking and immediate actions.

Alcamo (2008) examines the strengths and weaknesses of both qualitative and quantitative scenarios. The information below is adapted from that author's report. That author proposes a general procedure called "story and simulation," or SAS, approach for combining the two types of scenarios. The vital difference between qualitative and quantitative scenarios, as explained by Alcamo, is as follows: (1) a qualitative scenario communicates the complexity of, and internal linkages (or connections) within, the scenario; and (2) a quantitative scenario involves numerical data providing a check on the assumptions of the qualitative scenario. Thus, a qualitative scenario - the approach used in this chapter - permits the exposition of the essential features; while a quantitative scenario - not used in this chapter - functions as a testing of the assumptions (and associated outcomes).

An illustration is provided by Ralha and Abreu (2017). The information below is adapted from those authors' report. The MASE project includes a conceptual model characterizing individual behaviors and a computational tool for analyzing environmental scenarios. (The project addresses land change. MASE is an acronym for "Multi-Agent System for Environmental Simulation.") The MASE simulator can also implement the "Belief-Desire-Intention" (BDI) model, in the form of MASE-BDI. The authors tested the MASE and MASE-BDI simulators on two Brazilian cases. 


\section{THE ENVIRONMENTAL CATASTROPHE DYSTOPIAN NIGHTMARE}

The pessimistic scenario label "1984" draws directly and explicitly on the dystopian tradition associated with George Orwell's critiques of totalitarianism - 1984 (1949) and Animal Farm (1945). Conventionally, "1984" conveys bleakness. The optimistic scenario label "Brave New World" draws, ironically with intention, on Aldous Huxley's satire Brave New World (1932) (see Huxley, 1958). Such irony was intentional in H.G. Wells' The New Utopia (1905) -in content a precursor to Jack London's The Iron Heel (1908).

Jones and Warner (2016) identify three basic reasons for pessimism. First, world population will continue to increase to 10.9 billion by $2100 .{ }^{3}$ There will also be increasing per capita consumption: about one-fifth of the current population does not have electricity yet. Second, the necessary global energy mix - shifting away from fossil fuels - requires immediate heavy investment, unlikely to occur. Renewable energy production must be 87-94 percent of global energy consumption by 2100, rising from 9 percent in 2014. At least half (50 percent) of these renewable energy needs must occur at 2028 to hold global warming to 2 degrees centigrade or at 2054 to hold global warming to $2.5-3$ degrees centigrade. Third, governments have never met such a challenge; on the contrary, there are likely to be pressures to increase energy supply. Participating countries submitted, before or during the Paris conference, comprehensive national climate action plans titled Intended National Determined Contributions (INDCs) (UN Framework Convention on Climate Change, n.d.). The existing plans reportedly will not keep global warming below the 2-degree standard (European Commission, 2015).

Hardin (1974a, 1974b) developed an argument concerning the metaphorical "Spaceship Earth." Hardin makes three points. First, a spaceship would be directed by a captain, whereas the planet is actually a set of sovereign nations (some democratic, some dictatorial) not forming even a loose confederation. Second, the actual spaceship model thus results in a "tragedy of the commons" in which there is over-consumption and resource depletion. Third, a contrasting lifeboat metaphor involves multiple lifeboats and multiple swimmers not in lifeboats. The lifeboats are the set of nations that are sufficiently rich to float. The rich nations are about one-third of the whole set of nations. The swimmers are the poor nations, about two-thirds of the whole set of nations. The rich lifeboats (rich nations) should not help the swimmers (poor nations), as there are insufficient resources for everyone. In an environmental catastrophe, Hardin's lifeboat model may associate with "1984" repressive regimes as resources become insufficient even within lifeboats. 
The real-world instance of increasing disaster risk with climate change and rising sea level is the set of relatively low-lying Pacific and Indian Ocean islands. These islands already face the highest disaster risk per capita in the world (Noy and Edmonds, 2017). There was a 2009 tsunami in Samoa, 2014 floods in the Solomon Islands, and a 2015 cyclone striking Vanuatu (Noy and Edmonds, 2017). Noy and Edmonds argue that the main sources quantifying risk in the Pacific island region all underestimate risk. Four important trends signal increasing risk: (1) increasingly extremely hot days; (2) increasingly extreme rainfall events; (3) increasing cyclones; and (4) sea-level rise and other oceanic changes (Noy and Edmonds, 2017). The December 26, 2004 tsunami caused by an earthquake in the Indian Ocean killed nearly 230,000 (including missing in this count), including in Indonesia (Associated Press, 2017). Some island nations may disappear due to rising sea level, raising the issue of migration elsewhere.

Tsunami detection raises the issue - emphasized by Hardin - of financial assistance from rich nations. Let us assume that technology improvements can be applied by rich nations themselves, so that financial assistance is restricted to provision and maintenance. In Indonesia, a tsunami detection system has consisted of seafloor sensors communicating to transmitter buoys on the sea surface (Associated Press, 2017). The information below comes from Associated Press (2017). Germany and the USA provided 12 of the 22 buoys, but not maintenance support. Each buoy costs several hundred thousand dollars, and is operationally expensive. Communication to shore for timely warning is slow. It has been reported that all 22 buoys are inoperable, due partly to vandalism and due partly to a lack of funds for maintenance. In other words, Indonesia is not presently able (or perhaps willing) to maintain and operate the tsunami detection system that was installed. The USA National Science Foundation (NSF) has funded (\$3 million) the deployment of a prototype network of undersea sensors (between Padang and the Mentawai islands). ${ }^{4}$ This new system eliminates buoys, with undersea equipment instead sending data-bearing sound waves to the surface to refract back into the sea to travel the distance to the next network node. At the final node, only a short distance (a few kilometers) of fiber optic cable connects to a shore station. The data are then transmitted by satellite to a tsunami warning agency and to disaster officials in Padang.

There has been renewed attention (see Hall and Day, 2009) to the negative prediction made by The Limits to Growth simulation study published initially in 1972 (Meadows et al., 1972), updated through 2004 (Meadows et al., 2004). The simulation - a system dynamics computer model - predicted population, industrialization, pollution, food supply, and non-renewable natural resources depletion as key variables. The basic prediction was, absent sufficient change in conditions (characterized as 
a business-as-usual scenario or standard-run scenario), a serious decline within a century. Australian scholars have recently argued for validation of the predictions (Turner, 2008, 2014; Turner and Alexander, 2014). Turner's analysis compared historical data for 1970-2000 to the "limits to growth" scenario. He found that the historical data compared favorably with the standard-run scenario, but not with other scenarios that would reflect technology solutions or stabilizing behaviors and policies. The result is some form of collapse of the global system by about 2050. Turner emphasizes the importance of pollution.

\section{THE SUSTAINABLE DEVELOPMENT UTOPIAN DREAM}

While the Jones and Warner (2016) and "limits to growth" assessments are quite pessimistic, one can locate more optimistic assessments. For instance, Besley and Dixit (2017) construct a model of major environmental catastrophes emphasizing three features. (The authors solve the model numerically for plausible values of parameters in order to assess tradeoffs between alternative policies. The chief alternatives are prevention, mitigation, and technology.) One feature is distribution of possible damage. A second feature is that probability of an event increases with accumulating greenhouse gases. A third feature is that conservation is obviated if a technological solution emerges. The significant feature is technological innovation, for which a forecast as such is not possible within the constructed model. Technology is thus isolated, I think, as the vital element of sustainable development in the face of deteriorating environmental conditions.

The Brundtland Report on sustainable development (World Commission on Environment and Development, 1987), followed by the UN Sustainable Development Goals (2015), paints a feasible future in which actions can "end poverty, protect the planet, and ensure prosperity for all" (http://www. un.org/sustainabledevelopment/sustainable-development-goals/). The question addressed by this chapter concerns our knowledge of how to achieve sustainable development through key dimensions (businesses, consumers, institutions, and technology solutions). It is possible that pro-sustainability improvements through these dimensions will occur too slowly to prevent tipping points resulting in environmental dystopia.

The 1987 "Report of the World Commission on Environment and Development: Our Common Future" - commonly known as the Brundtland Report - introduced the following widely used conception of sustainable development (chapter 2): 
Sustainable development is development that meets the needs of the present without compromising the ability of future generations to meet their own needs. It contains within it two key concepts:

1. the concept of "needs," in particular the essential needs of the world's poor, to which overriding priority should be given; and

2. the idea of limitations, imposed by the state of technology and social organization, on the environment's ability to meet present and future needs.

This conception combines economic growth, environmental protection, and socio-economic equity: the triple bottom line of economy, environment, and society. That is, growth should occur to increase material wealth without damaging the natural environment and while increasing equity within societies. The Brundtland Report (1987, chapter 2) also argued that "Development involves a progressive transformation of economy and society." This concept of progressive transformation implies that social institutions will evolve, or can be changed more directly, over time. The Brundtland Report thus includes the problem of social institutions.

The UN Sustainable Development Goals (SDGs), adopted on September 25, 2015, aim at three outcomes: ending poverty (and associated problems), protecting the planet, and assuring prosperity. The three outcomes are captured as 17 SDGs, which can be measured. The set of SDGs is an action agenda for targets to be achieved by 2030 (that is, within 15 years). The 17 SDGs are listed below as ordered and labeled by the UN agreement.

1 - no poverty

2 - zero hunger

3 - good health and well-being

4 - quality education

5 - gender equality

6 - clean water and sanitation

7 - affordable and clean energy

8 - decent work and economic growth

9 - industry, innovation and infrastructure

10 - reduced inequalities

11 - sustainable cities and communities

12 - responsible consumption and production

13 - climate action

14 - life below water

15 - life on land

16 - peace, justice and strong institutions

17 - partnerships for the goals 
Schandl et al. (2016) argue that economic and environmental objectives are simultaneously achievable. The authors rely on two points: (1) well-designed policies can reduce both natural resource use and emissions; and (2) decarbonization and dematerialization can be achieved without loss of economic growth. The authors base their findings on a combined economic and environmental modeling approach involving 13 regions of the world as well as a global setting. The approach permits them to analyze natural resource use and carbon emissions by region and across three policy stylizations. The first stylized policy is the base case of no significant changes to environmental and climate policies: the current policies continue into the future. The second stylized policy is a "high efficiency" projection in which the global carbon price increases from $\$ 50$ to $\$ 236$ per ton between 2010 and 2050. Resource efficiency also increases, basically doubling or tripling over the historical figure. The third stylized policy - lying in between the base policy and the high efficiency projection - is a "medium efficiency" projection for global carbon price increase and resource efficiency increase. The authors conclude that global energy use rises rapidly under all scenarios, although carbon emissions can be reduced. They find that the OECD economies can decarbonize and dematerialize without impacting economic growth; while China can expand economic growth at a lower environmental cost. Even strong environmental policies do not much reduce economic growth and employment through 2050. It should be noted, however, that these scenarios combine resource efficiency improvements with carbon emission reductions, while increasing energy use supports economic growth and employment.

An illustration of this possibility is reported by Weldu and Assefa (2017). They study electricity supply in the province of Alberta, Canada. The following information is adapted from their report. Presently, over 80 percent of provincial electricity is supplied from fossil fuels, with coal providing 43 percent of the 80 percent. Alberta intends to stop using coal fully and rely on sustainable power production. The authors use an environmental life cycle costing approach to assess three biomass-based alternative scenarios, in comparison to the present coal-based scenario. The alternative scenarios all showed environmental life cycle improvements (ranging across the scenarios) for global warming, human health, and ecosystem impacts. (These results are not surprising.) However, the coal scenario is significantly less costly. On the other side of a cost comparison, two wood biomass-based alternatives cost less than some measures for average historical electricity generation cost for the province. That is, those alternatives may be more costly than coal but have better than average historical cost. There is an assessment of renewable energy alternatives in Europe (Berrill et al., 2016). 


\section{THINKING ABOUT "2084”: THE ROLES OF BUSINESSES, CONSUMERS, INSTITUTIONS, AND TECHNOLOGIES}

The year " 2084 " is used both (1) to move a century beyond 1984, and (2) to move 30 years beyond 2054, a date identified in Jones and Warner (2016) as a second critical point for climate change. (The first critical point is 2028, just short of the 2030 indicated in the Paris Agreement.) The year 2084 is in the future (to be determined), while " 1984 " is a totalitarian nightmare image.

Table 1.1 provides a possible " 2084 " global configuration structured in terms of "mega-blocs" and key policy problems. The policy problems are indicated along the horizontal stub of the table at the top. The four policy problems of interest are climate, trade and investment, migration, and violence. The mega-blocs or "mega-integration blocs" (Jovanovic, 2016) are listed down the vertical stub of the table at the left. The mega-blocs are presently identified as OECD/NATO (North America, Europe, Japan, Australia, and New Zealand), Russia, China, terrorists (whether terroristsponsoring states or non-state terrorist groups such as ISIS), OPEC (the key asset of which is a depleting resource - oil and gas), and other developing and emerging countries simply grouped here together for convenience. The initial three mega-blocs in Table 1.1 of course resemble Orwell's 1984 "Oceania" and "Eurasia" and "East Asia"; but the real world is presently more complicated. There are various environmental and trade agreements

Table 1.1 Possible "2084" global configuration in terms of "mega-blocs" and key policy problems

\begin{tabular}{|c|c|c|c|c|}
\hline \multirow[t]{2}{*}{ "Mega-Blocs" } & \multicolumn{4}{|c|}{ Four Key Policy Problems } \\
\hline & Climate & $\begin{array}{l}\text { Trade and } \\
\text { Investment }\end{array}$ & Migration & Violence \\
\hline \multicolumn{5}{|l|}{ OECD / NATO } \\
\hline \multicolumn{5}{|l|}{ Russia } \\
\hline \multicolumn{5}{|l|}{ China } \\
\hline \multicolumn{5}{|l|}{ Terrorists } \\
\hline \multicolumn{5}{|l|}{$\begin{array}{l}\text { OPEC: depleting } \\
\text { resource bloc }\end{array}$} \\
\hline \multicolumn{5}{|l|}{ Other developing } \\
\hline and emerging & & & & \\
\hline countries & & & & \\
\hline
\end{tabular}

Note: The term "mega-blocs" (or "mega-integration blocs") comes from Jovanovic (2016). Trade, investment, and migration are flows across national boundaries. 
negotiated prior to the 2015 Paris Agreement, such as the 1979 Convention on Long-Range Transboundary Air Pollution (Byrne, 2015).

Jovanovic's (2016) conception is that mega-integration blocs are emerging in what I characterize further in Table 1.1 as a multipolar world. The USA, European Union, and Japan combined can independently set rules for trade and investment, and also related dispute settlement. Their relative strength is enhanced if they cooperate, as in the OECD and NATO (of which Japan is not a member). Everyone else must comply or be excluded from potential benefits of interaction with the USA, European Union, and Japan. The risk is that some excluded players - for example, China, OPEC, and Russia - may be important enough to be able to create a different system in parallel. Jovanovic thinks in terms of bargaining among the mega-blocs, but argues that rules-setting is captured by big corporations. The reality that those disenfranchised in the rules-setting process are treated by big corporations as consumers rather than as citizens, tends to generate public resentment toward the dominant mega-blocs.

Within this conception of a multipolar world, there is a crucial question concerning whether there are sufficient incentives for effective cooperation. The Paris Agreement may be deceptive in this regard. Harvard economist Dani Rodrik states: "Countries have the right to protect their own social arrangements, regulations, and institutions. That's more important than squeezing out the last bit of purported efficiency gains from trade" (cited in Kuttner, 2017: 17). The Paris Agreement still involves some postponement of implementation for certain large developing countries, such as Brazil, India, and China. If anything, nationalism and patriotism may be increasing in international economic relationships (Windsor, 2017). The Obama Administration emphasized economic patriotism - especially for American multinational enterprises; the Trump Administration is emphasizing economic nationalism.

Eichner and Pethig (2017) formulate a model for addressing biodiversity conservation. In this model, rich countries (North lifeboats in Hardin's model) can afford to help pay for biodiversity conservation in poor countries (South swimmers in Hardin's model). The question is whether they will and if so how. In the model, biodiversity is a global public good, and this good is correlated with a share of land actively protected against deterioration. In the model, Regime 1 is a condition of no policy for supporting biodiversity conservation. In Regime 2, North countries do not coordinate conservation efforts. In Regime 3, North countries do coordinate.

We consider a world economy, in which the global public good "biodiversity" is positively correlated with that share of land which is protected by landuse restrictions against the deterioration of habitats and ecosystems. The willingness-to-pay for biodiversity conservation is positive in "rich" developed 
countries (North), but very low in "poor" developing countries (South). ... we analyze the changes in allocations and welfare when the North financially supports biodiversity conservation in the South. . . . We model that support as a market for biodiversity conservation and distinguish the cases, in which the North does (Regime 3) or does not (Regime 2) coordinate its biodiversity conservation actions. Our numerical examples exhibit various unexpected and even undesirable results. The move from Regime 1 [no policy] to Regime 2 hardly improves welfare and biodiversity in our examples irrespective of whether governments act strategically. That may explain the low level of the North's financial support of biodiversity in the South we observe in practice. Without strategic action, the move from Regime 1 to 3 enhances aggregate welfare, because Regime 3 is efficient, but the North or the South may be worse off due to unfavorable changes in their terms-of-trade. (Eichner and Pethig, 2017: 1)

The global environment is a complex system (or set of systems). Five key elements in how the global environment develops into the future are businesses, consumers, institutions (subdivided into governmental policies and non-governmental social institutions), and technologies. We do not understand enough concerning how each element functions in relation to global environmental outcomes, much less how the five elements interact in shaping that relationship.

Figure 1.2 provides a general depiction of the five elements in a proposed structuring. Technologies drive businesses toward becoming

Sources of Change Are

Not Well Understood

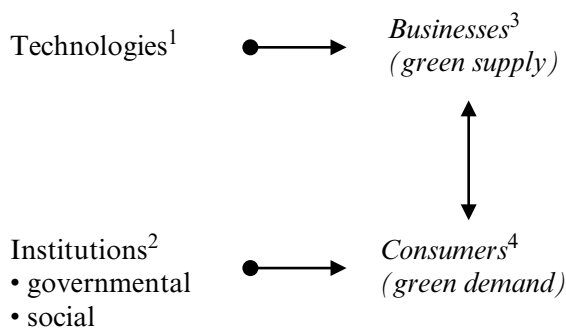

Markets

Notes:

1 Beder (1994) "The role of technology in sustainable development," Technology and Society.

2 Anderies (2015) "Understanding the dynamics of sustainable social-ecological systems: Human behavior, institutions, and regulatory feedback networks," Journal of Mathematical Biology; Bednar (2016) "Robust institutional design: What makes some institutions more adaptable and resilient to changes in their environment than others?" In Wilson and Kirman (eds.), Complexity and Evolution.

3 Oreskes and Schendler, "Corporations will never solve climate change," Harvard Business Review (blog).

4 Black and Cherrier (2010) "Anti-consumption as part of living a sustainable lifestyle," Journal of Consumer Behavior.

Figure 1.2 Roles of businesses, consumers, institutions, and technologies 
green suppliers. Institutions influence consumers toward becoming green demanders. The two types of institutions - governmental and other - are combined for convenience in the depiction. The sources of change in technologies and institutions are not well understood. Markets, shown in italics, are the interactions between businesses and consumers (both also shown in italics). Institutions and technologies may interact, but we do not know much about such interactions. Technologies may influence consumers, and institutions may influence institutions - but again we do not know much about such influences.

A crucial element in green behavior will be how businesses operate. There is a strong presumption in favor of corporate environmental and social responsibility (Kolk, 2016). But in reality, there are likely to be severe limits to business willingness to undertake anything other than profitable investments, the reason being that businesses are profit oriented, rather than altruistic organizations (Oreskes and Schendler, 2015; Strine, 2012).

Social enterprises and public-private alliances (Windsor, 2016a) may help fill the resulting gap, but may not be able to substitute sufficiently for businesses. Specific businesses - such as exotic tourism providers may adopt more environmentally sensitive approaches (Windsor, 2016b). There has been a profound split in sustainable development theorizing concerning the appropriate role of businesses in globalization: one school advocates relatively free markets for trade and investment; another school regards such markets as socially irresponsible (Barnett, 2004).

A missing aspect of the depiction in Figure 1.2 is how to promote collaboration and social learning among the various actors. Learning can be defined, following Romero-Mujalli et al. (2017), as modification of behavior due to experience. Such experience can be social (i.e., collective) or individual (i.e., asocial). Those authors argue that social learning may be superior to individual learning, particularly in the transmission of learning across generations into the future. The authors, using agent-based simulations, study this approach for a small population, so that interactions are both local and not fully experienced in environmental change. The results are quite interesting. Social learning enhanced survival (the measure of performance) for scenarios of static conditions and abrupt change. But individual learning enhanced survival for a scenario of gradual change. The authors conclude that a mixed population - of social and individual learners - survives best across possible conditions.

Businesses, consumers, and institutions (governmental and other) are likely to face increasingly VUCA conditions. VUCA stands for volatile, uncertain, complex, and ambiguous conditions. VUCA takes its definition as follows: 
It's an acronym developed by the U.S. military after the collapse of the Soviet Union to describe a multipolar world: volatile, uncertain, complex, and ambiguous. Volatility reflects the speed and turbulence of change. Uncertainty means that outcomes, even from familiar actions, are less predictable. Complexity indicates the vastness of interdependencies in globally connected economies and societies. And ambiguity conveys the multitude of options and potential outcomes resulting from them. Where once we could count on the seeming certainty and predictability of binary choices - capitalism versus communism, democracy versus autocracy, Corn Flakes versus kasha - choices and consequences are now far less clear. (McNulty, 2015)

\section{CONCLUSION AND IMPLICATIONS}

This chapter purposefully takes an "edgy" perspective on ecological sustainability and sustainable development. I proceed by contrasting pessimistic ("1984") and optimistic ("Brave New World") narratives in the form of qualitative scenarios. General narratives may tend to overemphasize positive or negative aspects for the purpose of supporting policy initiatives: positive in order to keep up the pace; negative in order to provoke action. The pessimistic scenario outlines steady movement toward global environmental catastrophe resulting from rising population and per capita consumption, and governmental failures to act sufficiently quickly to reduce emissions and invest in alternative renewable energy sources. Part of the reason for this "edge" view is that the other optimistic narrative emphasizes sustainable development. That is, development is encouraged and thought to be balanced against sustainability. There may be defects in the sustainable development approach, which optimists neglect. These two narratives are the extreme scenarios, within which empirical reality will enfold.

Scientific inquiry is about careful weighing of conceptualizations and empirical evidence. There is considerable reason to be "edgy" about "Our Common Future." We may be rapidly approaching global tipping points, against which much more drastic and rapid action may be necessary. The situation raises the question of whether the conventional approach international agreements, national implementation, and pro-sustainability admonitions and incentives - can work fast enough and effectively enough. The available pathways to sustainable development may be quite limited (Urry, 2010). The worse environmental conditions become, the more the available pathways may constrict in the future. However, these comments move toward forecast or prediction, as distinct from qualitative narrative.

The pessimistic scenario assumes that the key considerations-population, consumption, emissions, bad policies, and absence of technological fixes 
- will move against sustainable development. The optimistic scenario assumes that these key considerations will move away from environmental catastrophe and toward sustainable development. Empirically, we do not understand enough about five key elements and how they interact. These key elements are: businesses, consumers, institutions (subdivided between governmental institutions for setting policies and other institutions for influencing business and consumer behaviors), and technologies. Among these elements, there is reason for concern about whether businesses and consumers will adapt to "green" requirements. Governmental institutions may not act decisively. Technology is the swing element: it is unpredictable or uncertain; and it is the element on which implicit reliance may be placed in reality. One cannot discount technology (which is grounded in increasing scientific knowledge), but equally one cannot bet on technology.

\section{NOTES}

1. There was a reported explosion in the purchasing and reading of dystopian fiction linked to the election of Donald J. Trump as president (New York Times, 2017; Tuttle, 2017). A list of such key fiction, provided in the sources just cited, would include Margaret Attwood, The Handmaid's Tale (1985), Ray Bradbury, Fahrenheit 451 (1953), Aldous Huxley, Brave New World (1932), Aldous Huxley, Island (1962), George Orwell, Animal Farm (1945), George Orwell, 1984 (1949), and Sinclair Lewis, It Can't Happen Here (1935).

2. In Margaret Atwood's Oryx and Crake (2004), an attempt at utopia turns dystopian (Scott, 2017). Referencing Huxley, Orwell, and Atwood, Scott argues that both dystopia and utopia ultimately end in loss of empathy for others. The argument's foundation is that utopia goes "too far into ... dreams" while dystopia results in "a dark authoritarian regime" (Scott, 2017: 40).

3. The UN forecast is for 9.6 billion by 2050 (UN Department of Economic and Social Affairs, 2013). Then for the Jones and Warner (2016) figure, another billion would be added during the subsequent 50 years.

4. Padang is on the west coast of Sumatra facing the Indian Ocean. The Mentawai islands, a popular surfing area, are a chain of about 70 islands lying a little over 100 miles to the west of Sumatra. 